\title{
Comparison of High-Performance Ion Chromatography and absorptiometric methods for the determination of phytic acid in food samples
}

\author{
P. Talamond ${ }^{1, *}$, G. Gallon², J.P. Guyot ${ }^{1}$, I. Mbome Lape $^{3}$ and S. Trèche ${ }^{2}$ \\ ${ }^{1}$ Laboratoire de Biotechnologie Microbienne Tropicale, Centre ORSTOM de Montpellier, BP. 5045, \\ 911 avenue d'Agropolis, 34032 Montpellier Cedex, France \\ ${ }^{2}$ Laboratoire de Nutrition Tropicale, Centre ORSTOM de Montpellier, BP. 5045, 911 avenue d'Agropolis, \\ 34032 Montpellier Cedex, France \\ ${ }^{3}$ Food and Nutrition Research Centre, P.O. Box 6163, Yaoundé, Cameroon
}

\begin{abstract}
The objective of this paper consists in defining the interest of a new high-performance ion chromatography method (HPIC) with chemically suppressed conductivity detector for phytic acid determination in food samples. Firsly, accuracy and precision of the HPIC method have been measured. Secondly, The HPIC method and a classical absorptiometric method were compared. The HPIC method was more sensitive and selective than the absorptiometric method which leaded to an $27 \%$ overestimation of the phytic acid content in legume seeds. Because of it is rapid and easy to perform, the HPIC method appears to be particularly suitable for routine analysis of food samples.
\end{abstract}

Key words. Phytic acid - liquid chromatography - absorptiometry - food analysis.

\section{Introduction}

Phytic acid, myo-inositolhexaphosphate (Fig. 1), is a common constituent of many plant foods [1].This molecule is highly charged with six phosphate groups extending from the central inositol ring structure [2] and therefore is an excellent chelator of mineral ions [3]. Since phytate cannot be absorbed and humans have limited capacity for hydrolysing the phytate molecule, a negative effect of phytic acid on mineral bioavailability can be expected [4]. There have been numerous reports documenting a negative effect of phytic acid on the absorption of zinc, iron, copper and calcium $[5,6]$.

The classic methods for determination of phytic acid derives from the method of Heubner and Stadler [7]. These methods are based on the precipitation of ferric ion with phytate in dilute acid solution and analysis of phosphorus or iron in the precipitate $[8,9]$. One of the disadvantages of the iron precipitation methods is that not only inositol hexaphosphate is precipitated, but other phosphorus-containing compounds able to precipitate with ferric ion (i.e. inositol pentaphosphate and inositol tetraphosphate) as well [10]. Because of these disadvantages, HPLC methods were developed to improve the determination of phytic acid [11]. However, sample extracts must be first prepurified by passing through an anion-exchange resin to remove inorganic phosphate and concentrate inositol [12]. The first systems incorporated refractive index detection coupled with reversed-phase separation [13-17]. Spectrophotometric detection with post-column derivatization was later introduced to improve the analysis. The absence of chromophoric functional groups within inositol has led to the development of methods based on post-column derivatization and spec-

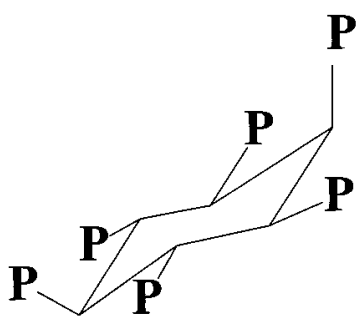<smiles>CO[P+]([O-])([O-])O</smiles>

Fig. 1. Structure of Inositol 1,2,3,4,5,6-hexaphosphate (or Phytic Acid).

trophotometric detection. Despite a high sensitivity of detection, the additional derivatization reaction constitutes a potential source of error and is also time-consuming. Rounds and Nielsen [18] have improved the separation by replacing the reversed-phase column by an anion-exchange one, thus suppressing the prepurification step. However, post-derivatization was still needed. A new method has been recently proposed by our laboratory based on a high performance ion chromatography (HPIC) following chemically suppressed conductivity detection $[19,20]$. This method does not require any prepurification and derivatization steps.

The objective of our study was the comparison of this HPIC method to the classical absorptiometric method.

* Correspondence and reprints

Received May 26, 1998; revised August 25, 1998; accepted September 8, 1998. 


\section{Materials and methods}

\section{Analytical instruments}

Beckman (Fullerton, USA) DU 70 spectrophotometer was used for colorimetric determination.

High Performance Ion Chromatography (HPIC) analyses were performed with a 4500i Dionex (Sunnyvale, USA) liquid chromatograph equipped with an eluent delivery pump, an autoinjector and using chemically suppressed conductivity. A $200 \mu \mathrm{L}$ constant volume injection loop was used throughout.

A centrifugal evaporator Jouan (France) RC10.10 fitted with a refrigerated trap cooled at $-60{ }^{\circ} \mathrm{C}$ was used for sample preparation. Sample solutions were diluted with a Gilson (Middleton, USA) semi-automatic dilutor 401 prior to injection.

\section{Reagents and solutions}

All chemicals used were of analytical grade and deionized water was used for preparing the reagent solutions. Deionized water was purified by Millipore ultra pure system to a specific resistance of $18 \mathrm{~m} \Omega-\mathrm{cm}$ or greater.

Sodium phytate (Sigma Ref. 3168) was used for the preparation of standard phytic acid solutions.

\section{Iron solution $\left(50 \mu \mathrm{g} \mathrm{m}^{-1}\right)$}

$625 \mu \mathrm{L}$ of concentrated $\mathrm{HNO}_{3}$ was added to $25 \mathrm{~mL}$ of a commercial standard iron solution $\left(\mathrm{Fe}^{3+} 1 \mathrm{~g} \mathrm{~L}^{-1}\right.$, Titrisol, Merck, Ref. 9972) and completed to $500 \mathrm{~mL}$ deionized water to give the final solution $\left(50 \mu \mathrm{g} \mathrm{mL}^{-1}\right)$.

\section{HPIC reagents}

The mobile phase was a mixture of three solutions A, B and C. Solution A was prepared by adding $10.4 \mathrm{~mL} \mathrm{NaOH}$ (commercial solution at $50 \%(\mathrm{w} / \mathrm{v})$ in water, Baker) in water (final volume: $1 \mathrm{~L}$ ). Solution B was deionized water:isopropanol 50:50 (v/v). Solution C was deionized water. Regenerated solution of anion suppressor was $50 \mathrm{mmol} \mathrm{L}^{-1}$ sulphuric acid solution. All the mobile phases were passed through a $0.45 \mu \mathrm{m}$ filter and degassed before use.

\section{Sample preparation}

Two flours were prepared from seeds of cowpea (Vigna unguiculata spp.) and millet (Pennisetum spp.) varieties cultivated in Senegal. As germination reduces phytate content of legume seeds and is likely to increase inositol penta or tetraphosphate, a flour from germinated cowpea seeds was also prepared by first soaking them in water for $24 \mathrm{~h}$ and keeping them wet at $28{ }^{\circ} \mathrm{C}$ during $48 \mathrm{~h}$ sprouting.

\section{Absorptiometric method}

Triplicate samples $(0.5 \mathrm{~g})$ of the freeze-dried, finely-ground products were extracted with $20 \mathrm{~mL} 0.5 \mathrm{~mol} \mathrm{~L}^{-1} \mathrm{HNO}_{3}$ for $3-4 \mathrm{~h}$ with continuous shaking. After filtering, phytate content determination was performed on the filtrate by a modification of the Holt's method (1955) [9].

The modified Holt procedure (1955) [8] adopted routinely in our laboratories for phytate contents determination was as follows: $0.2-0.5 \mathrm{~mL}$ of the filtrate or standard sodium phytate solution $\left(0.2 \mathrm{mmol} \mathrm{L}^{-1}\right)$ was diluted with distilled water to a final volume of $1.4 \mathrm{~mL}$. Then, $1.0 \mathrm{~mL}$ of a solution of ferric solution containing $50 \mu \mathrm{g} \mathrm{mL} \mathrm{mL}^{-1} \mathrm{Fe}^{3+}$ was added. After mixing, the test-tubes were capped, placed in a boiling water-bath for $20 \mathrm{~min}$, and cooled to room temperature. Five $\mathrm{mL}$ of amyl alcohol was added to each test-tube followed by $0.1 \mathrm{~mL}$ of a solution of ammonium thiocyanate $\left(100 \mathrm{~g} \mathrm{~L}^{-1}\right)$. The use of amyl alcohol recommended by David and Reid [9] consideraly improved the precision of the assay due to an increase in slope of the assay curve. The contents of the test-tubes were immediately mixed and centrifuged at $4000 \mathrm{~g}$ for $5 \mathrm{~min}$. The intensity of the colour in the amyl layer was determined at $465 \mathrm{~nm}$ using a spectrophotometer against an amyl alcohol "blank", exactly $15 \mathrm{~min}$ after the addition of $\mathrm{NH}_{4} \mathrm{SCN}$. Under these conditions an inverse relationship was found over a range of phytate concentrations from $0.0286 \mathrm{mmol} \mathrm{L}^{-1}$ to $0.114 \mathrm{mmol} \mathrm{L}^{-1}$.

\section{HPIC method}

\section{Phytate extraction}

The flour sample $(0.2 \mathrm{~g})$ was introduced in a Pyrex vial fit-

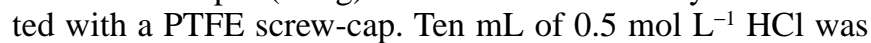
added and the vial was capped. The mixture was heated under stirring for $5 \mathrm{~min}$ by immersing the vial in boiling water. It was then centrifuged at $4000 \mathrm{~g}$ for $10 \mathrm{~min}$. The supernatant was recovered and $1.5 \mathrm{~mL}$ of $12 \mathrm{~mol} \mathrm{~L}^{-1} \mathrm{HCl}$ were added to obtain a $2 \mathrm{~mol} \mathrm{~L}^{-1} \mathrm{HCl}$ concentration in order to ensure the decomplexation of phytates. This procedure was found to allow the best extraction conditions. The resulting solution was then shaken and evaporated to dryness in a centrifugal evaporator. The vial was finally stored at $8{ }^{\circ} \mathrm{C}$.

Ten min before the injection, the residue was resuspended in $1 \mathrm{~mL}$ of deionized water and passed through a $0.2 \mu \mathrm{m}$ disposable filter (Acrodisc) tip-syringe assembly. The filtrate was then diluted in deionized water (1/50) and injected into the liquid chromatograph.

\section{Chromatographic conditions}

The separation was carried out on an Omnipac Pax-100 anion-exchange column $(25 \mathrm{~cm} \times 4 \mathrm{~mm}$ I.D., Dionex, Sunnyvale, C.A., USA) equipped with an Omnipac Pax-100 $(8 \mu \mathrm{m})$ precolumn and an anion suppressor (ASRS-I $4 \mathrm{~mm}$ ). Each eluent of the mobile phase was previously degassed in an ultrasonic bath and then introduced in the eluent delivery system under helium pressure.

The separation was performed by gradient elution using

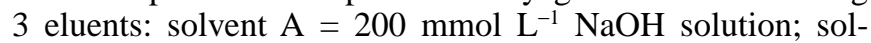
vent $\mathrm{B}=$ deionized Water-Isopropanol $(1: 1, \mathrm{v} / \mathrm{v})$; solvent $\mathrm{C}=$ deionized water.

After several assays, the gradient elution programme, shown in table I, was selected with a total chromatography run time of $15 \mathrm{~min}$.

The anion suppressor was continually regenerated with a $50 \mathrm{mmol} \mathrm{L}^{-1}$ sulphuric acid solution. Several solutions of phytic acid with concentrations from $0.01 \mathrm{mmol} \mathrm{L}^{-1}$ to $0.16 \mathrm{mmol} \mathrm{L}^{-1}$ were prepared from a standard solution for determination by calibration. 


\section{Original articles}

Table I. Gradient elution program for the separation of phytic acid.

\begin{tabular}{lcccc}
\hline $\begin{array}{l}\text { Elution } \\
\text { time (min) }\end{array}$ & $\begin{array}{c}\text { Flow rate } \\
(\mathrm{mL} / \text { min })\end{array}$ & $\% A$ & $\% B$ & $\% C$ \\
\hline 0.0 & 1 & 35 & 2 & 63 \\
2.0 & 1 & 54 & 2 & 44 \\
9.5 & 1 & 55 & 2 & 43 \\
10.5 & 1 & 35 & 2 & 63 \\
15 & 1 & 35 & 2 & 63 \\
\hline
\end{tabular}

\section{Statistical analysis}

The analysis of the variance (One way ANOVA) was carried out using the Sigmastat Software (Jandel) according to the conventional procedures.

\section{Results and discussion}

Firstly, we tested the linearity, accuracy, precision and reproducibility of the HPIC method. Secondly, we compared the results obtained on the samples by the absorptiometric and HPIC methods.

Phytic acid with concentrations ranging from $0.01 \mathrm{mmol}$ $\mathrm{L}^{-1}$ to $0.16 \mathrm{mmol} \mathrm{L}^{-1}$ was analysed on an anion exchange column with chemically suppressed conductivity detector using three solvents mixture for gradient elution. The more phosphate group were retained on the column. The elution of phytic acid was attained by $54-55 \% 200 \mathrm{mmol} \mathrm{L}^{-1}$ $\mathrm{NaOH}$ solution. An anion micromembrane suppressor (AMMS) was applied with conductivity detection. This suppressor was continually regenerated with $50 \mathrm{mmol} \mathrm{L}^{-1}$ sulfurid acid in order to neutralize. The use of suppressor reduces the conductivity of eluent and enhances the conductivity of the analytes. The retention time of phytate was $6.0 \pm 0.2 \mathrm{~min}$ with no day-to-day variation over a 5-month period (Fig. 2). The area under the conductivity peak is proportional to the phytic acid concentration over the entire range and correlation coefficients obtained are shown in table II. In order to determine whether $b(y=a x+b)$ was significantly different from 0 or not, the hypothesis $b=0$ [21] was tested. As the test was accepted, the calibration curves passing through zero can be used ( $y=a^{\prime} x$, Tab. II).

The variation coefficient of the instrument precision as calculated with the values of six injections of phytic acid was $0.57 \%$. To determine the method reproducibility, six different samples from the same batch of ungerminated cowpea (flour) were repeatedly analysed daily for four days. Precision for replicate injection $(n=24)$ was 5\% [relative standard deviation (R.S.D.) of repeatability] and 7\% (R.S.D. of reproducibility).

The HPIC method allows the quantitation of phytic acid down to $0.1 \mu \mathrm{mol} \mathrm{L}{ }^{-1}$. The signal-to-noise ratio was higher than 10: the limit of detection was therefore less than $0.0001 \mu \mathrm{mol} \mathrm{L}-1$.

Recoveries were determined by carrying out five extractions of the sample with increasing standard additions of a phytic acid solution $(33 \%, 50 \%, 66 \%, 100 \%$ of the initial

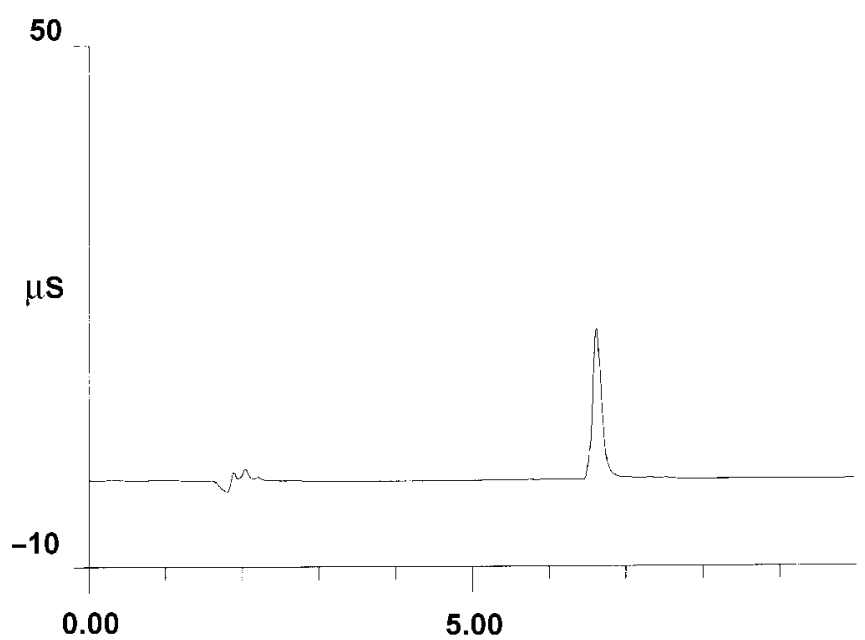

Fig. 2. Elution profile of phytic acid standard. Separation of phytic acid on an Omnipac Pax-100 column; eluents: $200 \mathrm{mM} \mathrm{NaOH}$, Water-Isopropanol $(1: 1, \mathrm{v} / \mathrm{v})$ and Water $(18 \mathrm{~m} \Omega)$; detection: chemically suppressed conductivity using and ASRS-I $4 \mathrm{~mm}$ ).

Table II. Statistical calculations on the regression between detector response (peak area) and phytate concentration.

\begin{tabular}{lcccc}
\hline$y=(a \pm s) x+(b \pm s)$ & Result $^{\mathrm{a}}$ & $y=\left(a^{\prime} \pm s\right) x$ & $R^{2}$ \\
\hline & \multicolumn{4}{c}{$a_{1} \pm s$} \\
\hline$(13592 \pm 157) x+(13.755 \pm 12.584)$ & $\mathrm{NS}$ & $(13180 \pm 106) x$ & 0.9992 \\
$(14194 \pm 164) x+(13.219 \pm 13.159)$ & $\mathrm{NS}$ & $(14317 \pm 109) x$ & 0.9995 \\
$(13937 \pm 127) x+(-3.098 \pm 10.237)$ & $\mathrm{NS}$ & $(13908 \pm 78) x$ & 0.9995 \\
$(14739 \pm 109) x+(2.767 \pm 6.193)$ & $\mathrm{NS}$ & $(14525 \pm 97) x$ & 0.9995 \\
& & $\boldsymbol{m}=\mathbf{1 3 9 8 3} \pm \mathbf{9 8}$ & \\
& & &
\end{tabular}

$s:$ Standard deviation.

a: Significance of the difference between $b$ and the null hypothesis $(b=0)$. NS: non significant.

$R^{2}$ : Correlation coefficient.

$m$ : Average value of four slopes.

concentration) and ranged between $100 \%$ and $105 \%$. Recoveries are independent of the amount of phytic acid applied, as is demonstrated by the linearity of the curve $\left(R^{2}=0.98\right)$.

Many workers [13-17] have determined phytic acid by using the reversed phase procedure in association with ionpair reagents. Nevertheless, pure reversed phase procedures showed only poor separations because the compounds were hardly retained on the stationary phase. Moreover, a prepurification step with a polystyrene-based strong anion exchange column prevents the potential problem of packing material deterioration, which could be encountered during prolonged use of a silica-based column with the mobilephase used, and concentrated the inositol phosphates. This step is time-consuming and prevented its use in routine. In agreement with Tangenjaja et al. [11], Graf and Dintzis [13] and Rounds and Nielsen [18], we observed with this HPLC methods two main disadvantages: poor separation and low sensitivity in the detection system (refractometric index). For these reasons, we decided to compare the HPIC method with 


\section{Original articles}

Table III. Accuracy and precision of methods (absorptiometric and HPIC).

\begin{tabular}{|c|c|c|c|c|c|}
\hline \multicolumn{3}{|c|}{ Colorimetric Method } & \multicolumn{3}{|c|}{ HPIC Method } \\
\hline $\begin{array}{l}\text { Phytate } \\
\left(\text { mmol L } L^{-1}\right)\end{array}$ & $\begin{array}{c}D . O^{\mathrm{a}} \\
465 \mathrm{~nm}\end{array}$ & Precision $^{\mathrm{b}}$ & $\begin{array}{c}\text { Phytate } \\
\left(\text { mmol L }^{-1}\right)\end{array}$ & $\begin{array}{c}\text { Peak area } \\
(\mu S)\end{array}$ & Precision $^{\mathrm{b}}$ \\
\hline 0 & $1.570 \pm 0.118$ & $9.33 \%$ & 0.01 & $138.62 \pm 4.71$ & $4.22 \%$ \\
\hline 0.0286 & $1.405 \pm 0.049$ & $4.34 \%$ & 0.02 & $294.62 \pm 9.36$ & $3.95 \%$ \\
\hline 0.057 & $1.179 \pm 0.064$ & $6.77 \%$ & 0.08 & $1140.72 \pm 35.55$ & $3.87 \%$ \\
\hline 0.0857 & $0.966 \pm 0.069$ & $9.29 \%$ & 0.1 & $1426.86 \pm 36.02$ & $3.14 \%$ \\
\hline 0.114 & $0.779 \pm 0.077$ & $13.0 \%$ & 0.16 & $2258.94 \pm 79.86$ & $4.39 \%$ \\
\hline
\end{tabular}

a Mean and Standard Deviation of five standards.

Precision $= \pm(t \times s x) / x$

$x$ : mean of 5 data.

$s x: s / 5$.

$t: 2.77 \overline{6}$.

the classical absorptiometric method for use in our laboratory.

We studied the two methods to determine their precision and accuracy for the determination of phytic acid and to select the most appropriate experimental protocol. Each sample of phytate standard solutions was prepared and analyzed in five replicate with HPIC and absorptiometric methods. The data of mean, standard deviation and precision by each method are shown in table III. The HPIC method was clearly more accurate than the absorptiometric method and could be directly applied to samples without prepurification.

Several kinds of cereals were extracted and phytate was quantified by the HPIC method and by the conventional absorptiometric method. Data obtained by the absorptiometric method, regardless of the cereal flour used, were systematically higher by about $27 \%$ than those of the HPIC method (Tab. IV). This result is in agreement with those of other authors [10,11,14-17] who obtained higher values with the absorptiometric method than reversed-phase method derives. This difference between the chromatographic and absorptiometric methods is not suprising in view of the fact that treatment of the extracts with the ferric solution: precipitates small amounts of inorganic phosphates and does not allow one to distinguish between different forms of phytate (particularly, pentaphosphate (IP5), tetraphosphate (IP4)) [22]. The ferric precipitation method cannot be used for the determination of phytic acid in all foods because the presence of interfering substances, such as reducing compounds leads to overestimated results.

\section{Conclusion}

The use of anion exchange chromatography with conductivity detection affords rapid separation of phytic acid without postcolumn derivatization. Moreover, this method does not require any sample prepurification.

Phytate contents can be determined with more convenience, precision and speed than the absorptiometric classic method. With the HPIC method the number of pre-chromatographic sample treatment steps are decreased (acid extraction, centrifugation and evaporation). This provides the
Table IV. Comparison of two methods for determining phytic acid in food samples.

\begin{tabular}{lccc}
\hline & \multicolumn{3}{c}{ Phytic acid $(\% \text { w/w })^{a}$} \\
\cline { 2 - 4 } Sample & $\begin{array}{c}\text { Absorptiometric } \\
\text { Method }(A)\end{array}$ & $\begin{array}{c}\text { HPIC } \\
\text { Method }(B)\end{array}$ & $\begin{array}{c}\% \text { of } \\
\text { overestimation }^{b}\end{array}$ \\
\hline Millet souna NG & $0.807 \pm 0.06$ & $0.587 \pm 0.06$ & 27.3 \\
Cowpea NG & $1.32 \pm 0.03$ & $0.97 \pm 0.02$ & 26.5 \\
Millet souna G & $0.49 \pm 0.07$ & $0.351 \pm 0.02$ & 28.6 \\
\hline
\end{tabular}

${ }^{\mathrm{a}}$ Mean $\pm \mathrm{SD}$ of three replicate samples.

b \% percent difference between the absorptiometric and the HPIC methods: $100-(B \times 100 / A)$.

analysis of phytic acid with an additional alternative to the existing methods.

\section{References}

1. Posternak, S. C. R. Soc. Biol. 1903, 55, 1190.

2. Johnson, L. F.; Tale, M. E. Can. J. Chem. 1969, 47, 63.

3. Vohra, P.; Gray, G.; Kratzer, F. H. Proc. Soc. Expl. Biol. Med. 1965, 47, 63 .

4. Besançon, P. In: L'alimentation de complément du jeune enfant, Trèche, S.; de Benoist, B.; Benbouzid, D.; Verster, A.; Delpeuch, F. Eds., Orstom éditions, Paris, 1995; p 105.

5. Nolan, B.; Duffin, P. A.; Mc Weeny, D. J. J. Agric. Food Chem. 1975, 23, 1186.

6. Oberleas, D. $2^{\text {nd }}$ Ed. National Academy of Science, Washington DC, 1973; p 363.

7. Heubner, W.; Stadler, H. Biochem Z. 1914, 64, 422.

8. Holt, R. J. Sci. Food Agric. 1955, 6, 136.

9. Davies, N. T.; Reid, H. Br. J. Nutr. 1979, 41, 579.

10. De Boland, A. R.; Garner, G. B.; O’Dell, B. L. J. Agric. Food Chem. 1975, 23, 1186.

11. Tangendjaja, B.; Buckle, K. A.; Wootton, M. J. Chromatogr. 1980, 197, 274.

12. Cosgrove, D. J. Biochem J. 1963, 89, 172.

13. Graf, E.; Dintzis, F. R. J. Agric. Food Chem. 1982, 30, 1094. 


\section{Original articles}

14. Sandberg, A. S.; Ahderinne, R. J. Food Sci. 1986, 51, 547.

15. Graf, E.; Dintzis, F. R. Anal. Biochem. 1982, 119, 413.

16. Marquié, C.; Segueilha, L.; Moulin, G.; Vialettes, V.; Galzy, P. Coton Fibres Trop. 1995, 97, 289.

17. Matthaüs, B.; Loïsing, R.; Fiebig, H. J. Fat. Sci. Technol. 1995, 97, 289.

18. Rounds, M. A.; Nielsen, S. S. J. Chromatogr. A 1993, 653, 148.
19. Skoglung, E.; Carlsson, N. G.; Sandberg, A. S. J. Agric. Food Chem. 1997, 45, 431.

20. Talamond, P.; Gallon, G.; Trèche, S. J. Chromatogr. A 1998, 805, 143-147.

21. Miller, J. C. In: Statistics for analytical chemistry, Miller, J. N. Eds., Ellis Horwood, John Wiley, 1984.

22. Lönnerdal, B. O.; Sandberg, A. S.; Sandström, B.; Kunz, C. J. Nutr. 1989, 119, 211. 